\title{
TÜRKÇEDE VE ALMANCADA SES BENZEŞIMI
}

\author{
Adnan ALDEMIR*
}

\begin{abstract}
ÖZET
Bu çalışmada Almanca ve Türkçedeki ses benzeşimi (Lat. assimilare), bir başka deyimle asimilasyon, dildeki pragmatik olarak zordan kolaya doğru geçişi ifade eden ses değişimi ve benzeşim olayı eşsüremli (synchronisch) olarak incelenmiştir. Aynı zamanda dilden kaynaklanan, dillerin bağlantıll, eklemeli ya da bükünlü olmasından kaynaklanan bir ses benzeșimi söz konusudur. Ses benzeșimleri aynı zamanda dil ağızlarında görülen bir ses olayıdır. Yer yer bu ses benzeşim olaylarını ortaya koymak için artsüremli (diachronisch) sözcük örnekleri de verilmiştir.

Anahtar Sözcükler: Ses benzeşimi (asimilasyon), artsüremli, eşsüremli, pragmatik, bağlantılı dil, bükünlü dil, ă̆ız, ses değişimi
\end{abstract}

\begin{abstract}
In this study, the voice simulations in German and Turkish (Lat. assimilare), in other words assimilations, the phonetic change in language which represents the transition from difficult to simple pragmatically and the assimilation were investigated as synchronical. At the same time there is a assimilation caused by language, the assimilation caused by agglutinating and inflected language. The assimilations are sound events which also seen in local dialects. From place to place in order to demonstrate that sound simulation events are examples of the diachronic words.

Keywords: assimilation, diachronic, synchronical, pragmatic, agglutinatived language, inflected language, dialect, phonetic change.
\end{abstract}

\section{GİRIS}

Ses benzeşimi (Lat. assimilare "benzer kılmak”, Akkomodation, benzeşim, erime (Verschmelzung) ve geçiş (Überführung) anlamlarına gelir. Fonolojide bu kavram çoğunlukla Koartikulation (artikulatorik basitleşme) yoluyla oluşan dildeki ses değişimi olarak tanımlanır. Drosdowski (1989)'ye göre “As|si|mi|la|ti|on die; -,en <»Benzer kılma«>: 1. a) benzeşim, uyum; b) Bir ünsüzün bir başkasına uyumu (.örn. Almanca sözcük Lamm Orta Yüksek Almanca lamb'dan gelir)". Burada $b$ ünsüzünün $m$ ünsüzü ile ses benzeşim olayı söz konusudur. Ses benzeşimi Vardar ve ark. (1988)'na göre “'Bir sesin söz zincirinde kendisinden önce ya da sonra gelen bir başka sesle birlikte bulunmasından doğan ve birinden öbürüne özellik aktarımı yoluyla gerçekleşen değişim” olayına verilen addır.

$\mathrm{Bu}$ çalışma ses benzeşimlerini betimleyici yönetme göre tanımlarken, dildeki ses benzeşimlerinden kaynaklanan bir takım yanlışlıkları, dildeki ses benzeşim örnekleriyle yönelimleri ortaya koymaktadır. Bu çalışmanın dilbilime katkısı ise örneğin Türkçedeki ses benzeşimleri sonucunda yanlış kullanımları da ortaya koyarken güzel, doğru Türkçenin

*Dr., MEB Hayatboyu Öğrenme Genel Müdürlüğü, adnan.ald@gmail.com 
kullanımına da katkıda bulunmaktadır. Bu çalışma Almanca ve Türkçedeki ses benzeşimlerinin bu dillerin özelliklerinden de kaynaklandığını ortaya koymaktadır. Aynı zamanda bazı yöresel ağızlardaki ses benzeşim örneklerini de vermektedir. Bu çalışma ses benzeşim türlerini betimlemek amacıyla alan yazınından alıntılarla desteklenirken, çalışmada bizzat dile getirilen örneklerle ses benzeşim olayları daha

somut örneklerle ortaya konulmuştur.

Almanca ve Türkçede aşağıda karşılaştırmalı olarak ele alınan ve analiz edilen şu benzeşim türleri vardır:

\section{BENZEŞIM TÜRLERI}

\subsection{Genizsileșme}

"Genizsileşme (Nasalisierung) ağız kapalı olmaksızın seslerin çıkarılmasında genizin bu olaya katılmasıdır. (Örn. "Chance" sözcüğünde hemen yanında bulunan nasal ses /n/ önündeki /a/ ünlüsündeki gibi.).”1

Nasal seslerden önce gelen ünlüler genizsileşir.

Türkçede

bẹn, sẹn, șen, Cẹm

bin, sin, cin, kin

kin, can, kạn, şan

hem, kem, dẹm, ham $\underline{\text { Almancada }}$

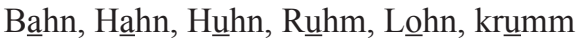

Freundin, Lehrerin, Ärztin, hịn, rennen

Leistung, Übung, Verantwortung

Form, Norm, Kern, Gehirn, Bịrne, Lehm

\subsection{Genizsi Benzeşim}

Genizsi benzeşim (Nasale Assimilation ) olayında Türkçede /n/ ünsüzü /m/ ünsüzüne benzeşir. Genel olarak/p/ ve /b/ ünsüzlerinden önce gelen $/ \mathrm{n} /$ ler $/ \mathrm{m} /$ ye dönüşür. Böyle bir benzeşim Almancada da görülmektedir.

Türkçede

onbir $\rightarrow$ ombir

canbaz $\rightarrow$ cambaz

binbir $\rightarrow$ bimbir
Almancada

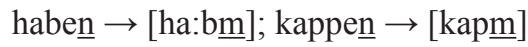

"Wappen $\rightarrow$ [vapm] ]" (Martens, 1965)

Sappen $\rightarrow$ [sapm $] \quad$ Mappen $\rightarrow[$ mapm $]$

\subsection{Damaksılaşma}

Damaksılaşma (Palatasierung) "Çevre seslerinin çıktığı yere (Artikulationsort) uyum nedenlerinden dolayı dil arkasının gerilmesi ile sert damak doğrultusunda bir sesin çıktığı yere bağlı olarak değişimidir.” 2

Türkcede

kăğıt $\rightarrow$ kâăğt

layık $\rightarrow$ lâyık

$$
\begin{array}{ll}
\quad \underline{\text { Almancada }} & \\
\text { lesen } \rightarrow \text { lesen } & {[\text { le:sən] }} \\
\text { gehen } \rightarrow \text { gehen } & \text { [ge:ən] } \\
\text { nehmen } \rightarrow \text { nehmen } & \text { [ne:mən] }
\end{array}
$$


Almancada /h/ ünsüzünün önünde duran /e/ ünlülerinde incelme (Erhellung) olay1 sonucunda Türkçe/i/ sesi gibi telaffuz edildiği görülmektedir.

\section{4. İleriye Doğru Benzeşim}

Illeriye doğru benzeşim (Progressive Assimilation), bir sözcük ya da bir sözcük grubundan önce gelen bir sesin kendinden sonra gelen bir sesi etkilemesi olayıdır. Almancada tek heceli sözcüklerin çoğullarıyla sözcüklerin ilk sesiyle son sesinde görülür.

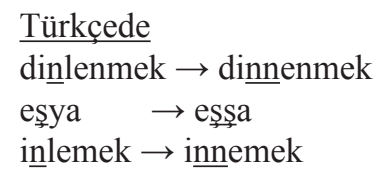

setzt sich $\quad[\mathrm{tz}] \rightarrow[\mathrm{ts}]$ frisch sein $\left[\int \mathrm{z}\right] \rightarrow\left[\int_{\mathrm{s}}\right]$ umbenennen $[\mathrm{mb}] \rightarrow[\mathrm{mm}]$ (Kohler, 1977)

$$
\begin{aligned}
& \text { Almancada } \\
& \text { dasselbe }[\mathrm{sz}] \rightarrow[\mathrm{ss}] \\
& \text { Haus } \rightarrow \text { Häuser } \\
& \text { das Siebengebirge [sz] } \rightarrow \text { [ss] } \\
& \text { Büch } \rightarrow \text { Bücher } \\
& \text { Huhhn } \rightarrow \text { Hühner } \\
& \text { Ball } \rightarrow \text { Bälle }
\end{aligned}
$$

\subsection{Geriye Doğru Benzeşim}

Geriye doğru benzeşim (Regressive Assimilation) bir sözcük ya da bir sözcük grubundan sonra gelen bir sesin kendinden önce gelen sesi etkilemesi olayıdır. Rothenhagen (2002)'a göre "İleriye doğru benzeşim, ilk sesin bir sonraki sesi etkilemesi olayıdır. Geriye doğru benzeşim ise, ikinci sesin önceki sesi etkilemesi olayıdır."

$$
\begin{aligned}
& \text { Türkçede: } \\
& \text { kazsin } \rightarrow \text { kassin } \\
& \text { bu ile } \rightarrow \text { böyle } \\
& \text { şu ile } \rightarrow \text { şöyle } \\
& \underline{\text { o ile }} \rightarrow \text { öyle }
\end{aligned}
$$

Almancada:

Signal [gn] $\rightarrow[\mathrm{gn}]$ werden $[\mathrm{dn}] \rightarrow[\mathrm{nn}]$

Türkçede "bu ile” örneğinde olduğu gibi, ön sesli olan /e/ art sesli olan /u/ yu /ö/ ünlüsüne dönüştürür. Bu durum [şu ile] örneğinde de görülmektedir. /y/ ise bağlama ünsüzü görevindedir. [Kazsın] örneğinde ise /s/ ünsüzünün geriye doğru /z/ ünsüzüne benzeşmesi söz konusudur.

Almanca örneklerde görüldüğü gibi "Nasal sesinin önündeki ötümlü patlamalı ünsüz nasal sesine dönüşebilir.” (Kohler, 1977)

\section{6. Ünlülerarası Ötümlüleşme}

Ünlülerarası ötümlüleşme (intervokalische Senorisierung) ötümsüz sürtüşmeli (frikativ) ve patlamalı (plosiven) ünsüzlerin ötümlülüşme olayıdır. 
Türkçede:

oțag $\rightarrow$ oda

kulüp $\rightarrow$ kulübü

katife $\rightarrow$ kadife

kap $\rightarrow$ kab 1

hap $\rightarrow$ hab 1

kitap $\rightarrow$ kitab
Almancada:

Das muss ich machen. [z]

Das hat er doch gemacht. [d]

Das schaff ich doch nicht. [v]

\section{7. Ünlü Uyumu}

Almancada olmayan ünlü uyumu Türkçede iki kısma ayrılır:

\subsubsection{Büyük Sesli Uyumu}

Türkçede büyük sesli uyumu (Palatalharmonie, große Vokalharmonie) bir sözcüğün ilk hecesindeki ünlü kalınsa, ondan sonra gelen bütün hecelerin ünlüleri de kalın; ilk hecenin ünlüsü inceyse, ondan sonra gelen bütün hecelerin ünlülerinin de ince olmasıdır.

Örn. kedi, tüylü, irilerini, biçimli, açılır, vd.

\subsubsection{Küçük Sesli Uyumu}

Vardar ve ark. (1988), küçük sesli иуитипu (Labialharmonie, kleine Vokalharmonie) “Türkçede yalın ya da eklerle uzatılmış bir sözcüğün ilk hecesinde düz ünlü varsa, sonraki hecelerde de dar yuvarlak ya da geniş düz ünlüler bulunması yoluyla oluşan uyum.” şeklinde açıklamaktadır.

Örn. oralar, etler, ergen, uygun, vd.

\subsection{Son Ünlü Silinmesi}

Son ünlü silinmesini (Elision), Vardar ve ark., (1988) "Bir sözcüğün sonunda yer alan bir ünlünün bir sonraki sözcügün başında bulunan ünlünün etkisiyle düşmesi” şeklinde tanımlamaktadır.

Kohler (1977), bu olayı “Almancada iki /ə/ ünlüsünün her biri nasal ünsüzünün önünde bulunursa, ikinci /ə/ ünlüsü düşer” şeklinde açıklamaktadır.

Almancada:

auf ebenem Boden

die abgeschnittenen Rosen

$$
\begin{aligned}
& {[\underline{\text { bənəm }}] \rightarrow[\mathrm{bnm}]} \\
& {[\text { tənən }] \rightarrow[\mathrm{tnn}]}
\end{aligned}
$$

Burada da bu değişikliğin ve ses benzeşmesinin dildeki kolaylığa doğru geçiş eğiliminden kaynaklandığını görüyoruz.

\section{DİĞER SES OLAYLARI}

Ergin (1985)'e göre “Sözcüklerin ve sözcük dışında kalan diğer gramer birliklerinin kuruluşunda ve hayatında, seslerin belirli şartlar altında birleşmelerinin ve birlikte yaşamalarının gereği olarak görülen" diğer ses olayları şunlardır: 


\subsection{Son Ses Düşmesi}

Vardar ve ark. (1988)'na göre son ses düşmesi (Apokope), “Bir sözcüğün son sesinin kullanılmaz olması olayıdır.” Türkçede /r/ ünsüzünde, Almancada /e/ ünlüsünde görülür.

Türkçede

$$
\begin{aligned}
& \text { serbest } \rightarrow \text { serbes } \\
& \text { geliyor } \rightarrow \text { geliyo } \\
& \text { bir } \rightarrow \text { bi } \\
& \text { kışlağ } \rightarrow \text { kışla } \\
& \text { sor } \rightarrow \text { so } \\
& \text { okuyor } \rightarrow \text { okuyo } \\
& \text { geliyor } \rightarrow \text { geliyo } \\
& \text { yazıyor } \rightarrow \text { yazıyo }
\end{aligned}
$$

$\underline{\text { Almancada }}$

$$
\begin{array}{ll}
\text { zu Hause } & \rightarrow \text { zu Haus } \\
\text { dem Kinde } & \rightarrow \text { dem Kind } \\
\text { Niederlande } & \rightarrow \text { Niederland } \\
\text { Norde } & \rightarrow \text { Nord } \\
\text { Lande } & \rightarrow \text { Land } \\
\text { Dorfe } & \rightarrow \text { Dorf } \\
\text { dem Manne } & \rightarrow \text { dem Mann }
\end{array}
$$

\begin{tabular}{|c|c|c|}
\hline Türkçede & & Almancada \\
\hline $\begin{array}{l}\text { arslan } \rightarrow \text { aslan } \\
\text { şurada } \rightarrow \text { şurda } \\
\text { alı̄n } \rightarrow \text { alnı } \\
\text { gönülüm } \rightarrow \text { gönlüm } \\
\text { karı̣n } \rightarrow \text { karnı }\end{array}$ & $\begin{array}{l}\text { hoghh } \\
\text { wollet } \\
\text { du sonnest } \\
\text { sollet } \\
\text { dunkel } \\
\text { Wille } \\
\text { Adel } \\
\text { Schule } \\
\text { Miete } \\
\text { Knuspe } \\
\text { Sonate }\end{array}$ & $\begin{array}{l}\rightarrow \text { höher } \\
\rightarrow \text { wollt } \\
\rightarrow \text { du sonnst } \\
\rightarrow \text { sollt } \\
\rightarrow \text { dunkler } \\
\rightarrow \text { willkommen } \\
\rightarrow \text { adlig } \\
\rightarrow \text { Schulklasse } \\
\rightarrow \text { Mietvertrag } \\
\rightarrow \text { knusprig } \\
\rightarrow \text { Sonatine }\end{array}$ \\
\hline
\end{tabular}

Buradaki örnekleri incelediğimizde Almancada bu benzeşim olaylarının genel olarak artsüremli, Türkçedeki ses benzeşim olaylarının ise genelde eşsüremli olarak geliştiğini söylemek mümkündür. Bu tür ses değişimleri itibariyle Türkçedeki ses değişim olaylarının daha hızlı geliştiğini, Almancadaki bu ses değişim olaylarının ise uzun vadede gerçekleştiği sonucunu çıkarabiliriz. Örneğin yukarıda örnek olarak verilen Türkçe sözcüklerdeki son ünsüzün benzeşmesi ve düşmesi olayı eşsüremli gelişen ve aynı zamanda dildeki çabuk değişimi ve bozulmayı da yansıtan somut örneklerdir. /r/ ünsüzünün telaffuzu genel olarak zor olmasından kaynaklanan bir tarzda Almancada son ünsüz olarak /r/'nin genelde üzerine bastırmadan, peltek bir biçimde telaffuzu da benzer bir durumu yansıtmaktadır. Almancada yukarldaki örneklerde geçen sözcüklerin sonundaki le/ ünlüsünün düşmesi ve ses benzeşim olayı artsüremli olarak gelişmiştir.

\section{2. İç Ses Düşmesi}

Vardar ve ark. (1988)'na göre iç ses düşmesi (Synkope, Ausstoßung) “Sözcük içindeki bir sesin kullanılmaz olması olayıdır." 
Iç ses düşmesi olayı her iki dilde de sözcüğe sondan bir takım ünlülerin ya da biçimbirimlerin eklenmesi durumunda gerçekleştiği görülmektedir. Örn. [alın] sözcüğüne /1/ ünlüsü eklendiğinde sözcük içinde yer alan /1/ sesi düşmektedir. Benzer bir durum [karın] $\rightarrow$ [karn1] örneğinde de görülmektedir. Burada da /1/ sesi düşmüştür. Almancadaki örneklerde de [hoch] sözcügüne /-er/ sıfatın daha üstünlük derecesi (Komparativ) geldiğinde /c/ ünsüzü düşmektedir. Benzer bir durum [dunkel] sözcüğünde de görülmektedir. Burada da /-er/ takısı geldiğinde sözcük içinde yer alan /-e/ ünlüsü düşmüştür. Örn. bileşik sözcük türetiminde [Wille] $\rightarrow$ [willkommen] sonda yer /e/ ünlüsünün düştüğünü görmekteyiz. Benzer bir durum [Schule] sözcüğü için de geçerlidir. Bu sözcügün sonuna yeni bir sözcük [Klasse] eklendiği zaman /e/ ünlüsünün düşme olayı gerçekleşmektedir. [Adel] sözcüğünün sonuna [-ig] sıfat türetim eki geldiği zaman da sözcük içinde yer alan /e/ ünlüsü düşmektedir. Bu tür ses değişim olayları Türkçe ve Almancada görülebilen için ortak özelliklerdir.

\subsection{Ses Türemesi}

(Vardar ve ark., 1988)'na göre ses türemesi (Anaptyxe) “Bir sözcükte söyleyişi kolaylaştırıcı bir sesin, genellikle de bir ünlünün ("Sproßvokal”) ortaya çıkması olayıdır."

\subsection{1. Ön Türeme}

Vardar ve ark. (1988)'na göre ön türeme (Prothese) “Bir sözcüğün önünde kökensel olmayan bir ses oluşmasıdır. Almancada bu tür türemeye ancak şivelerde rastlanır. „, Bir ünsüzün ön türemesi hecenin başında gerçekleşir. Ortografik olarak onu çoğunlukla hecenin ünlüsü izler.

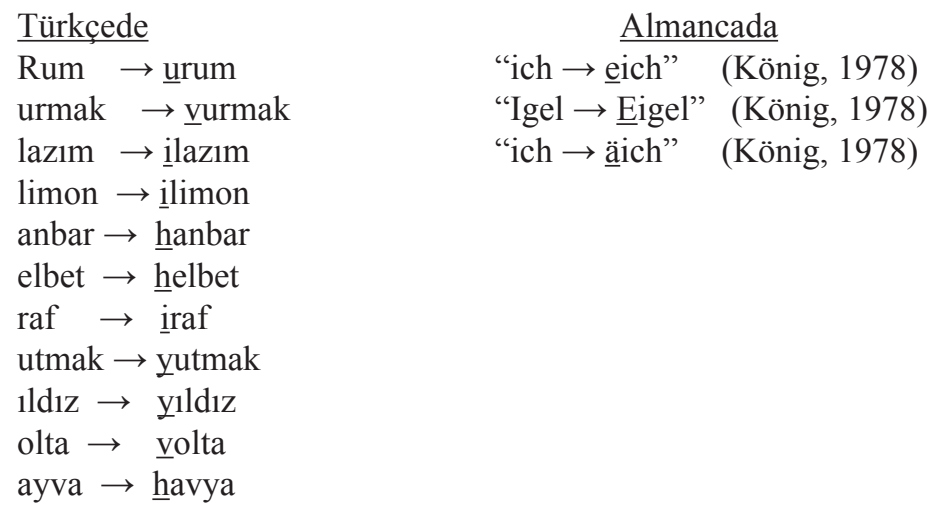

Türkçedeki örnekleri ele aldığımız zaman [urmak] sözcüğünün [vurmak] biçiminde bugün Türkiye Türkçesinde kullanıldığını görüyoruz. [utmak] sözcüğü de [yutmak] olarak bugünkü Türkçede kullanılmaktadır. Aynı şekilde [1ldız] da [yıldız]; [olta] ise [volta] biçimine dönüşmüştür. Diğer örnekler ise yöresel, ağız biçiminde kullanılmaktadır. Örn. [hayva], [iraf], [helbet], [ilimon], [ilazım] ve [urum] gibi. Bu tür bir kullanımı Kemaliye yöresi ağılarında görmekteyiz.

"Kemaliye ăgzının en belirgin özelliklerinden biri de ses eklemleridir. Özellikle “ $r$ ” ve " $\mathrm{l}$ ” sesi ile başlayan sözcüklerin başına i-u-ü gibi seslerin eklenmesidir. Örneğin [limon] yerine [ilimon], [Rus] yerine [Urus], [Rum] yerine [Urum], 
[rüya] yerine [ürüya], [Ramazan] yerine [İramazan] denilebilmektedir.”3

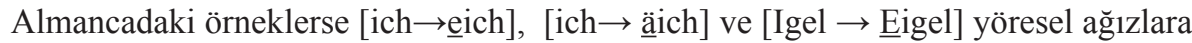
dayanır.

\subsection{2. İç Türeme}

Vardar ve ark. (1988)'na göre iç türeme (Epenthese, Einschub) “Bir sözcüğün içinde kökensel olmayan bir sesin oluşması" olayıdır.

Türkçede:

$\begin{array}{llll}\text { faide } & \rightarrow \text { fądda } & \text { mai } & \rightarrow \text { mayi } \\ \text { kılıç } & \rightarrow \text { kılınç } & \text { zaif } & \rightarrow \text { zayif (zayıf) } \\ \text { kızamık } & \rightarrow \text { kızambik } & \text { fiat } & \rightarrow \text { fiyat } \\ \text { puan } & \rightarrow \text { puanan } & \text { psikoloji } & \rightarrow \text { pisikikoloji } \\ \text { tren } & \rightarrow \text { tịren } & \text { laik } & \rightarrow \text { layik } \\ \text { daire } & \rightarrow \text { dayre } & \text { klise } & \rightarrow \text { kilise } \\ \text { ait } & \rightarrow \text { ayit } & & \end{array}$

Almancada:

"Bruder $\rightarrow$ Brauder $\rightarrow$ Broder $\rightarrow$ Bruẹder $\rightarrow$ Brüeder

müde $\rightarrow$ mua $\rightarrow$ müe $\rightarrow$ miad $\rightarrow$ möid

dreschen $\rightarrow$ droschen $\rightarrow$ draschen" (König, 1978)

Almancada iç türeme örnekleri genel olarak artsüremli (diachronisch) olarak görülmektedir. Türkçede ise [faide $\rightarrow$ fayda], [puan $\rightarrow$ puvan], [tren $\rightarrow$ tiren] sözcüklerindeki ses değişimi yabancı sözcüklerin telaffuz zorluğunun aşılması amacıyla gerçekleşen pragmatik nedenlerle dil değişiminden kaynaklanmaktadır ve bu örnekler eşsüremli ses benzeşimlerine somut örneklerdir. Sözcügün içinde kökensel olmayan ama telaffuzu kolaylaştırıcı bir ses eklenmektedir. Yukarıdaki örneklerde [y/v/i] seslerinin eklendiğini görüyoruz. Aynı durum [daire ve ait] sözcüklerinin değişime uğrayarak [dayre] ve [ayit] şeklinde kullanımında da görülmektedir. Bu iki sözcük içinde telaffuz zorluğundan kaynaklanan /y/ ünsüzünün oluştuğu ve kullanılageldiği görülmektedir.

\subsubsection{Son Türeme}

Son türeme (Vokalepithese) "Bir sözcüğün sonunda kökensel olmayan bir sesin belirmesidir.” (Vardar ve ark., 1988). Bu ses olayı ile ilgili aşağıdaki örnekler verilebilir:

Türkçede:

kehrüba (Farsça) $\rightarrow$ kehrübar (Türkçe) 1978)

peyda $\quad$ (Farsça) $\rightarrow$ peydah (Türkçe) $\underline{\text { Almancada }}$

“Junge $\rightarrow$ Junger " (König,

ward $\rightarrow$ wurde (artsüremli)

(Korkmaz, 1992) ağızlarda çok az rastlanan sondaki ünlü türemesinin yazı dilinde örneğinin bulunmadığını belirtir. 
[Junge] sözcüğü eski Almancada [Junger] olarak kullanılmıştır. Almancada bugün kullanılan [wurde] sözcügüüün eskideki kullanım biçimi [ward] /e/ sesi eklenmesi ile [wurde] halini almıştır.

\subsection{Göçüşme, Yer Değiştirme}

Göçüşme, ses aktarımı veya yer değiştirme (Lautversetzung) (Vardar ve ark., 1988)'na göre "Bir sözcük içinde birbirini izleyen iki sesbiriminin yer değiştirmesidir." (Vardar ve ark., 1988) hece düşmesi olayını "göçüşme" olarak nitelerken, (Ergin,1985) bu olayı "yer değiştirme" olarak niteler.

Türkçede

yalniz $\rightarrow$ yanliz

kibrit $\rightarrow$ kirbit

karyola $\rightarrow$ kayrola

memleket $\rightarrow$ melmeket

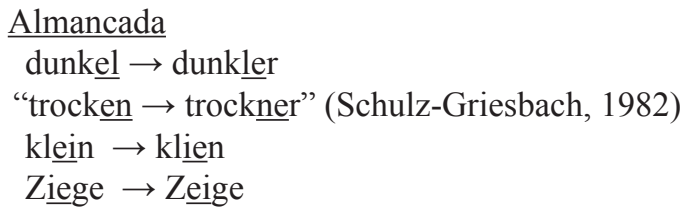

Yukarıdaki örneklerde [yalnız $\rightarrow$ yanlız] bir yanlış kullanımı göstermektedir. Örneğin [yanlış] sözcüğü de hatalı kullanım nedeniyle bazen [yalnış] olarak kullanılmaktadır. Aynı şekilde [kirbit], [kayrola] ve [melmeket] sözcüklerinde de bir yanlış kullanım söz konusudur. Örneğin "yeri kazıp derinleştirme, kazı” anlamına gelen [hafriyat] sözcüğü yanlış kullanım nedeniyle bazen [harfiyat] olarak gerek yazılı gerekse de sözlü ifadelerde yer alabilmektedir. Burada bir takım ses benzeşimlerinin dildeki hatalı kullanımların yaygınlaşması sonucu ortaya çıktığını da söylemek mümkündür.

Almancada [dunkel $\rightarrow$ dunkler] örneğinde /-er/ sıfat daha üstünlük derecesi eklendiğinde /e/ ünlüsünün düşmesi olayı gerçekleşir. Benzer bir durum [trocken $\rightarrow$ trockner] sözcüklerinde de vardır. [klein $\rightarrow$ klien] ve [Ziege $\rightarrow$ Zeige] örnekleri ise yöresel şiveleri yansitmaktadir.

\subsection{Hece Düşmesi}

Hece düşmesi (Silbenschichtung) bir sözcükte artarda gelen ve ses bakımından birbirine benzeyen iki heceden birinin düşmesi olayıdır.

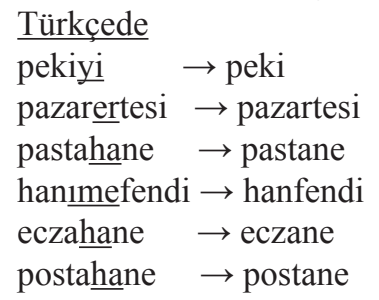

Almancada yalnızca bileşik sözcüklerde örneğin [Gehweg, Kaufhof, Spaziergang] bileşik sözcüklerinde [-en] mastar eklerinin düşmesi gibi hece düşmesi görülmektedir. Ama artsüremli örneklere de rastlanır.

Türkçedeki örneklerde ise pragmatik nedenlerle örneğin [hane] sözcüğündeki [-ha] hecesinin düşmesi Türkçedeki genel eğilimi yansıtmaktadır. [pekiyi] sözcügündeki [-yi] 
hecesi ise kolaylaştırıcı kullanımsal bir değişikliktir. [pazarertesi] bileşik sözcüğünde ise Almancadaki bileşik sözcüklerin türetimine benzer bir durum vardır. Bileşik sözcük oluşumunda [-er] hecesi düşmüştür.

\subsection{Benzeşmezlik, Aykırılaşma}

Bir benzeşme kuralına uymaksızın "bir sözcükte yan yana gelmiş aynı cinsten iki sesin birbirinden ayrılması"(Ergin, 1985) diye tanımlanan benzeşmezlik, aykırılaşma'ya (Entähnlichung, Dissimilation) "benzeşmeme” de denilebilir. Türkçe ve Almancada nadir olarak rastlanır.

$$
\begin{aligned}
& \text { Türkçede } \quad \text { Almancada } \\
& \text { attar } \rightarrow \text { aktar } \quad \text { Schwiegermutter } \rightarrow \text { Schwiegermuater" (König, 1978) } \\
& \text { așc1 } \rightarrow \text { ahç1 } \\
& \text { fincan } \rightarrow \text { filcan } \\
& \text { zelzele } \rightarrow \text { zerzele } \\
& \text { murdar } \rightarrow \text { mundar }
\end{aligned}
$$

[Schwiegermuater]'deki [muater] ve “[muoter]”(Folz,1987) olarak bir benzeşmeme yansıtarak Orta Yüksek ve Eski Yüksek Almancada kullanılmıştır. Buradaki aykırılaşma artsüremli olarak gerçekleşmiştir.

Yukarıda yer alan [attar] sözcüğü TDK güncel sözlüğüne göre kullanılmamakta, [aktar] ise aşağıdaki anlamlara gelmektedir: "1. isim Baharat veya güzel kokular satan kimse veya dükkân 2. İğne, iplik, baharat, zarf, kâğıt, tütün vb. satılan dükkân" ${ }^{4}$

Nitekim [ahçı] sözcüğü TDK güncel sözlügüünde yer almamaktadır.

Benzeşmezlik ile oluşan [filcan], TDK Derleme Sözlüğü c. 12'ye göre Yozgat, Lefkoşe, Kıbrıs'ta kullanılmaktadır. ${ }^{5}$

[Mundar] sözcüğü, [mundar getirmek] deyimi şeklinde Isparta yöresinde [TDK Derleme Sözlügü c: 9 ] olarak kullanılmaktadır. Örn. Uzancaburç Silifke İçel'de [mundar ölmek] deyimsel anlamda "1. Kimsesiz, yanında dua okunmadan ölmek." [ TDK Derleme Sözlüğü c: 12 ] şeklinde kullanılmaktadır. ${ }^{6}$

\section{7. İkileme}

İkileme (Verdoppelung) bir ünsüzün iki kez söylenmesi olayıdır. Genelde ünsüzlerde görülür. Türkçe ve Almancada nadiren rastlanan bir ses olayıdır.

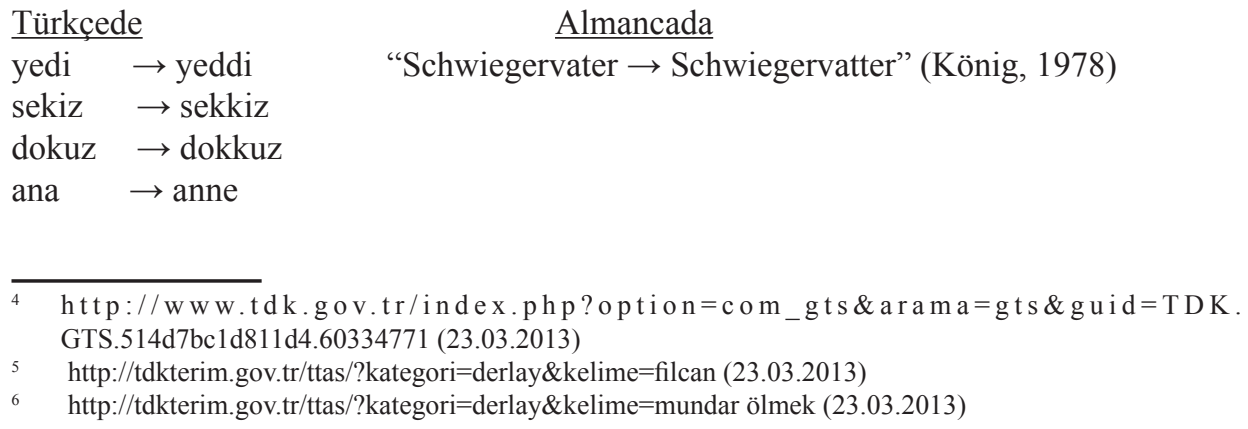

4 http://www.tdk.gov.tr/index.php?option=com_gts\&arama=gts\&guid=TDK. GTS.514d7bc1d811d4.60334771 (23.03.2013) 
Almancada görülen [vatter] ikileme örneği sık görülmeyen bir ses olayıdır.

[yeddi] sözcüğünün Karakoyunlu Kars, Erzurum; Urfa Merkez; Elazı̆̆ yörelerinde kullanımı görülmüştür. [Sekkiz] ise Erzurum, Artvin ve Keban bölgesinde kullanılmaktadır. [Dokkuz] şeklinde ikileme kullanımı ise Antakya/Hatay, Doğu Trakya, Erzurum, Diyarbakır, Çermik, Artvin yörelerinde ağız olarak kullanıldığı görülmüştür. ${ }^{7}$

Eskiden yaygın olarak kullanılan [ana] sözcügünün yerine bugün Türkiye Türkçesinde [anne] sözcüğü kullanılmaktadır. TDK Türkiye Türkçesi Ağızları Sözlüğü’nde [ana] sözcügünün [anne] anlamında Diyarbakır, Isparta, Bilecik, Çanakkale, Doğu Trakya, Erzurum, Keban, Diyarbakır, Ordu yörelerinde kullanıldığını belirtmektedir. ${ }^{8}$ Ama bununla birlikte Türkiye'nin hemen hemen tüm yörelerinde [ana] sözcügünün kullanıldığ 1 da görülmektedir. [Anne] sözcüğü ise Türkiye Türkçesinde yazılı ve sözlü iletişimde en yaygın bir biçimde kullanılmaktadır.

İki dilde yer alan bu ikileme ses benzeşim olayının genelde eşsüremli bir süreçte gerçekleşmesi iki dildeki bu alandaki benzerliği yansıtmaktadır.

\subsection{Tekleşme}

Tekleşme (Degemination) adı verilen bu ses olayı, iki ünlü ya da iki ünsüzün yakın bir ünlü ya da ünsüze dönüşmesi olayıdır.

\begin{tabular}{|c|c|}
\hline Türkçede & Almancada \\
\hline $\overrightarrow{\text { hammal }} \rightarrow$ hamal & 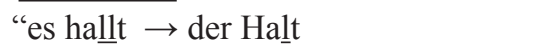 \\
\hline$\rightarrow$ kere & $\begin{array}{l}\text { es wallt } \rightarrow \text { der Wald" (Mertens, 1965) } \\
\text { beharren } \rightarrow \text { [be'hart] }\end{array}$ \\
\hline
\end{tabular}

Almanca örneklerde görülen tekleşme genelde artsüremli bir değişime dayanır. Ve bununla birlikte yeni bir sözcük oluşumunda görülmektedir. [behart] örneğindeki tekleşme ise hatalı kullanımı göstermektedir. ${ }^{9}$

Bugünkü Türkiye Türkçesinde [hamal] sözcüğü kullanılırken, TDK Türkiye Türkçesi Ağıları Sözlüğü’nde [hammal] sözcügünün Erzurum yöresinde kullanıldığg belirtilmektedir. ${ }^{10}$

[Kere] sözcüğü bugünkü Türkiye Türkçesinde kullanılırken [kerre] sözcüğü Malatya yöresinde görülür. ${ }^{11}$

\subsection{Kaynaşma}

Vardar ve ark. (1988)'na göre kaynaşma (Fusion) “bir sözcükte yan yana bulunan iki öğenin çözümleme yapamayacak denli iç içe girmesi” olayıdır.

Türkçede

Almancada

ne $\underline{\text { için }} \rightarrow$ niçin $\quad$ kahve altı $\rightarrow$ kahvaltt

gibt $\underline{\text { es }} \rightarrow$ gibt's

ne oldu $\rightarrow$ noldu

geht es $\rightarrow$ geht's

\footnotetext{
http://tdkterim.gov.tr/ttas/ (23.03.2013)

http://tdkterim.gov.tr/ttas/?kategori=derlay\&kelime=ana (23.03.2013)

http://synonyme.woxikon.de/synonyme/behart.php (23.03.2013)

http://www.tdkterim.gov.tr/ttas/?kategori=derlay\&kelime=hammal (23.03.2013)

http://www.tdkterim.gov.tr/ttas/?kategori=derlay\&kelime=kerre $(23.03 .2013)$
} 
Türkçedeki örneklerde /e/ ünlülerinin kaynaşarak, bir sonraki sözcüğün ilk ünlüsünü almaları söz konusudur. Almancadaki örneklerde ise, /e/ ünlüsü kaynaşmış ve yanı başındaki ünsüz /s/ bir önceki sözcükle birlikte kullanılmaktadır.

\subsection{0 İki Ünlünün Yan yana Gelmesi}

Bu olay, iki ünlünün arasında bulunan ünsüzün erimesi sonucu ortaya çıkar.

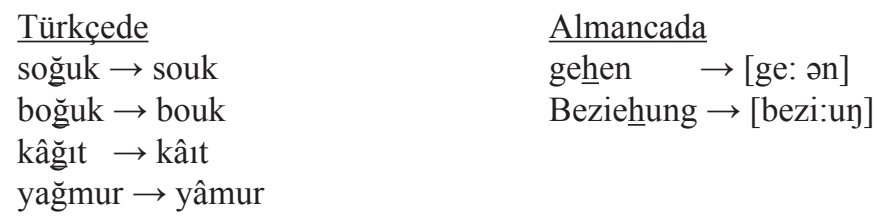

İki ünlünün yan yana gelmesi olayı Türkçede ve Almancada görülen bir olaydır. Türkçede genel olarak / $\breve{g} /$ ünsüzünde görülürken, Almancada ise $/ \mathrm{h} /$ ünsüzünde görülür. Türkçede ünlü telaffuzunda uzama görülmezken, Almancada /e/ ünlüsünde ve /ie/ çiftünlülerinde (Diphthong) görüldüğü gibi telaffuzda ünlüler yukarıdaki [ge: ən] ve [bezi:u门] sözcüklerindeki gibi yarım ses uzatılır. Türkiye Türkçesi Ağıları Sözlügü’nde [souk] sözcügünün Uşak yöresinde; [yâmur] sözcüğünün ise Kandıra Kocaeli'nde görüldüğü belirtilmektedir. [Yamur] olarak da Ordu ve çevresinde saptanmıştır. ${ }^{12}$

\subsection{Orta Hece Ünlüsünün Değișmesi}

İki ve ikiden çok heceli sözcüklerin orta hece ünlüsünde bazen oluşan değişikliklerdir. Orta hece ünlüsünün değişmesi (Veränderung des Innensilbenvokals) Almancada sıfatların derecelendirilmesinde ve çoğul adlarda görülür.

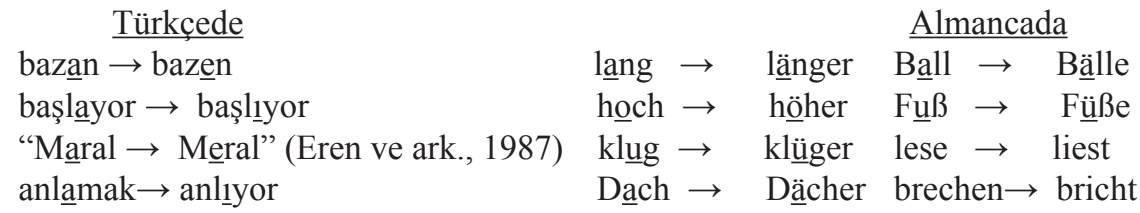

[bazan] sözcüğü Diyarbakır ve Erzurum yöresinde kullanılmaktadır.

[başlayor $\rightarrow$ başlı́yor]; [anlamak $\rightarrow$ anlı̄yor] örneklerinde ünlü daralması söz konusudur. [Maral $\rightarrow$ Meral] örneğinde ise ünlü incelmesi vardır.

Almancada ise orta hece ünlüsünün değişmesi, bükünlü bir dil olması açısından genel olarak fiil çekimlerinde, isimlerin çoğullarında, sıfatların derecelendirilmelerinde görülür. Türkçede bağlantılı bir dil olması dolayısıyla bu tür bir orta hece ünlüsünün değişmesi görülmez.

\subsection{Yuvarlaklaşma}

Bazı sözcüklerde dudak ve dudak-diş ünsüzleri düz ünlüleri yuvarlaklaştırır. Almancada

12 http://www.tdkterim.gov.tr/ttas/?kategori=derlay\&kelime=yâmur (23.03.2013) 
bu tip yuvarlaklaşma görülmez.

$\begin{array}{lllll}\text { "kilim-im } & {[\text { kilim-im] }} & \text { 'mein Teppich' } & \text { köy-üm [køy-ym] } & \text { 'mein Dorf' } \\ \text { k1z-1m } & {[\text { kwz-wm] }} & \text { 'mein Mädchen' } & \text { koz-um [koz-um] } & \text { 'meine Walnuss } \\ \text { ev-im } & {[\text { ev-im] }} & \text { 'mein Haus' } & \text { gül-üm [gyl-ym] } & \text { 'meine Rose } \\ \text { kaz-ım } & {[\text { kaz-wm }]} & \text { 'meine Gans' } & \text { kuş-um [kuş-um] } & \text { 'mein Vogel' }{ }_{13}^{13}\end{array}$

\section{SONUÇ}

Bir dilin temel yapı taşları olan sesler, yine o dilin temel ses kuralları içerisinde ahenkli bir biçimde bulunmakta; kök, ek, hece, sözcük ve sözcük gruplarını oluşturmaktadır. Bu oluşumda birbirlerinden oldukça etkilendiklerini görmekteyiz. Bu etkileşimde dildeki doğal değişim ilkelerinden olan zordan kolaya ilkesi temel etmenlerdendir. Aynı zamanda dilin özelliklerinden kaynaklanan örneğin Almancanın bükünlü dil olmasından kaynaklanan sıfatların daha üstünlük derecelerinde, çoğullarda ve fiil çekimlerinde görülen isimlerin köklerindeki değişiklikler, dildeki ses değişim olaylarını yansıtmaktadır. Ama Türkçe bağlantılı bir dil olması açısından bu tür bükünlülük özelliklerini göstermez. Almanca ve Türkçedeki bileşik sözcük türetimlerinde bazen sözcüklerin son eki ya da son hecesinin düştüğünü görmekteyiz. Örn. [Pazarertesi $\rightarrow$ Pazartesi gibi]. Bu da iki dilde aynı nedenden kaynaklanan ses benzeşimlerinin de gerçekleştiğini göstermektedir. Almancadaki ses benzeşimlerinin büyük bir kısmının artsüremli, Türkçedeki ses benzeşimlerinin de daha ziyade eşsüremli olarak gerçekleştiği de bir başka önemli husustur. Bu da Türkçedeki kimi ses benzeşimlerinin daha kısa süreçte gerçekleştiğini de göstermektedir. Ses benzeşim olaylarının en yoğun olarak görüldüğü alan ise dilin ağızlarındaki farklı kullanım türleridir. Bu gerek Almanca, gerekse de Türkçede çok yaygın ses benzeşim ortamını yansıtmaktadır. Eğer bir dili güzel kullanmak ve bir dile hakim olmak, aynı zamanda bir dili doğru anlamak, etkin bir biçimde kullanmak isteniyorsa, bu dilin ses kuralları ve ses değişim olayları, yöresel ağızlar da çok iyi bilinmelidir.

\section{KAYNAKÇA}

Drosdowski, Günther. (1989) Duden Deutsches Universalwörterbuch, 2. bask1, Mannheim, s. 145.

Eren, Hasan; Zülfikar, Hamza. (1987). Türk Dili I, Ankara: Açık Öğretim Fakültesi Yayınlar1, No: 111, s. 8.

Ergin, Muharrem. (1985). Türk Dil Bilgisi, İstanbul: Boğaziçi Yayınları, s. 51, 52, 53.

Folz, Jürgen. (1987). Schülerduden Wortgeschichte Herkunft und Entwicklung des deutschen Wortschatzes, Mannhemi: Duden Yayınevi, s. 334.

Kohler, Klaus J. (1977). Grundlagen der Germanistik Einführung in die Phonetik des Deutschen, gözden geçirilmiş 4. baskı, Marburg: N. G. Elwert Yayınevi, s. 210, 214,217, 218.

König, Werner. (1978). DTV- Atlas zur deutschen Sprache, 1. bask1, Münih: Deutscher Taschenbuch Yayınevi, s. 146, 148, 150, 155, 162, 166, 168, 229.

Korkmaz, Zeynep (1992). Gramer Terimleri Sözlüğü, Ankara: Türk Dil Kurumu Yayınları, s.136.

Martens, Carl und Peter. (1965). Phonetik der deutschen Sprache, Münih: Max Hueber

13 http://www.uni-leipzig.de/ jtrommer/phonologie06/p24.pdf (23.03.2013) 
Yayınevi, s. 237, 241.

Rothenhagen, R. (2002). Phonetischer Grundkurs der deutschen Sprache für Tschechischsprecher, Brno, s.36, 39.

Schulz, Dora; Griesbach, Heinz. (1982). Grammatik der deutschen Sprache, 11. bask1, Münih: Max Hueber Yayınevi, s. 126.

Vardar, Berke; Güz, Nüket; Öztokat; Senemoğlu, Osman; Sözer, Emel.(1988). Açıklamalı Dilbilim Terimleri Sözlüğü, İstanbul: ABC Kitabevi, s. 42, 109, 124, 138, 148, 161, 182, 186,187, 247. 
